\title{
O BANCO CENTRAL DO BRASIL COMO AGENTE DAS RELAÇõES INTERNACIONAIS
}

\author{
Mauro Salvo ${ }^{1}$
}

\section{Introdução}

A motivação para escrever este artigo me foi dada por um trecho do livro de Amado Cervo "O Desafio Internacional" que diz que os técnicos do BACEN e do Ministério da Fazenda tomaram o lugar do Itamaraty nas negociações econômicas no âmbito internacional, referindo-se a dicotomia entre tratamento político ou técnico a ser dado à questão da dívida externa brasileira.

"A Nação e com ela o nacionalismo foram afastados das negociações da dívida, uma vez que o Congresso e a Chancelaria nada tinham a dizer. $\mathrm{O}$ tratamento político que era reclamado internamente e alardeado pela diplomacia nos foros latinoamericanos era uma farsa. A condução das negociações fora confiada aos economistas da Fazenda e do Banco Central e sempre se manteve em suas mãos, mesmo porque não se poderia dar a tão grave assunto dois tratamentos diferentes." (Cervo 1994, 49)

Tendo como ponto de partida a assertiva acima resolvi testar a hipótese de que o BACEN é um agente das relações internacionais. Para atingir o objetivo serão encadeados no decorrer do texto fatos históricos e ilações teóricas. Inicialmente será abordado como os temas econômicos ampliaram seu espaço nas relações internacionais no período do pós II guerra e ainda mais no pósguerra-fria em detrimento dos temas relativos a segurança nacional. Além disso,

\footnotetext{
${ }^{1}$ Banco Central do Brasil. Doutor em Economia (UFRGS). E-mail: msalvo@terra.com.br
} 
muitos dos temas econômicos relevantes no cenário mundial contemporâneo referem-se a atribuições dos bancos centrais nacionais.

Os bancos centrais trabalham cada vez mais num contexto internacional e não apenas em bases bilaterais. Bancos centrais que atuam com independência tendem a desenvolver suas próprias posições, além de terem construído uma consistente e autônoma rede de relações. Neste caso, independência significa não ingerência de outras instituições domésticas no cumprimento das metas e missões dos bancos centrais. Nos últimos anos novos grupos, fóruns e organismos foram criados, nos quais os bancos centrais têm sido altamente presentes (por exemplo, G-20 e o Comitê de Estabilidade Financeira).

Quais são as questões pertinentes aos bancos centrais no plano internacional? É possível que questões relacionadas a um problema técnico aparentemente pequeno possam mascarar um debate fundamental até então não formulado, ou ser revelado por este. Temas importantes não necessariamente geram diferenças de opinião, por isso deve-se negociar para alcançar um consenso consistente, evitando bloquear soluções devido a princípios excessivamente rígidos. Todavia, os bancos centrais que atuam sem princípios que definam sua linha política correm o risco de não manter a coerência quanto aos pontos de vista expressos ou posições adotadas. Mesmo operando de forma independente, os bancos centrais devem manter a coerência com a posição nacional geral, incluindo as posições dos diversos ministérios e autarquias.

A legislação brasileira (principalmente a Constituição Federal e a Lei 4595/64) atribui ao BACEN as funções de atuar na política cambial e nas relações financeiras do Brasil com o exterior. Mais especificamente suas funções consistem em manter ativos de ouro e de moedas estrangeiras para atuação nos mercados de câmbio, de forma a contribuir para manter a paridade da moeda e para induzir desempenhos das transações internacionais do País, de acordo com as diretrizes da política econômica. Assim como atuar regulando o mercado de câmbio, buscando o equilíbrio do balanço de pagamentos, administrando as reservas cambiais do País, acompanhando e controlando os movimentos de capitais, negociando com as instituições financeiras e com os organismos financeiros estrangeiros e internacionais (Fundo Monetário Internacional - FMI, Bank for International Settlements - BIS etc.) e gerenciando convênios internacionais de créditos recíprocos (CCR). Quando surgem dificuldades no 


\section{Mauro Salvo}

balanço de pagamentos, cabe ao BACEN contratar no exterior as operações de regularização: os empréstimos compensatórios.

Todavia, pretende-se neste artigo levar a discussão além da evidência legal. Pretende-se demonstrar que a democratização, a globalização, a conscientização sobre a necessidade de aumentar a transparência nas relações financeiras, econômicas e políticas e o crescimento da cooperação internacional fortaleceram tanto as instituições internacionais como as domésticas ou aumentaram a necessidade de que os países que desejam inserir-se globalmente desenvolvam instituições fortes, entre elas, seus respectivos bancos centrais.

$O$ artigo não seguirá uma corrente única de pensamento, nem no que tange a teoria econômica nem quanto à teoria das relações internacionais. Buscar-se-á agregar contribuições de diferentes linhas ideológicas que ajudem a sustentar um posicionamento coerente que se aproxime ao máximo de uma conclusão.

Do Realismo aproveitaremos a idéia de que o sistema internacional é essencialmente "anárquico", ou seja, não há um governo mundial. De forma mais ampla, as relações internacionais são compreendidas tomando-se por base a distribuição de poder entre os Estados. Apesar da igualdade legal e formal, a distribuição de poder desigual indica que a arena das relações internacionais pressupõe uma "política de poder". (Griffiths 2004, 11).

Ao contrário dos realistas, os liberais consideram as relações internacionais como um campo em potencial para o progresso e as mudanças vantajosas. Os liberais crêem que apesar das dificuldades em estender em termos internacionais as restrições dadas pela necessidade de respeito às exigências do mercado econômico e as regras de lei, essas últimas devem ser estabelecidas para promover a estabilidade entre os Estados. (Griffiths 2004, 83).

Os pensadores da teoria crítica mostram como as relações internacionais entre os Estados possibilitam as injustiças do sistema capitalista global. Os pesquisadores que abordam a organização internacional estudam como as relações entre Estados são regulamentadas pelas organizações e práticas de cooperação. (Griffiths 2004, 161, 255).

No cenário interno, os problemas enfrentados pelo Brasil nas últimas décadas, adicionados do acima exposto, contribuíram para evidenciar o papel e a importância de uma instituição forte como o BACEN. Cabe ressaltar que o 
BACEN promoveu ajustes em sua forma de atuar ao longo destes anos a fim de manter-se em consonância com os desafios impostos pelas circunstâncias nacionais e internacionais.

Deve-se atentar para o fato de que a importância crescente do BACEN como agente das relações econômicas do Brasil com o resto do mundo fez-se por duas vias. Tanto de forma passiva por decorrência da evolução das relações internacionais, como ativa em decorrência de sua atuação.

\section{Crescente Poder da Economia nas Relações Internacionais}

Para a teoria marxista a economia é o motor da história. No entanto, a Teoria das Relações Internacionais até meados do século XX concentrou as explicações do sistema internacional na questão da segurança nacional e conseqüentemente em aspectos ligados a guerra e a paz. Todavia com o fim da guerra fria, aumento da globalização e consolidação da democracia em diversos países. os interesses econômicos das empresas transnacionais, bem como a busca por melhora do bem estar por parte de governos democráticos, reforçou a intenção em manter a paz mundial e direcionar investimentos na produção de bens para o consumo em vez de bens voltados para a guerra.

Qual seria a configuração do mundo se três das assunções centrais do Realismo fossem invertidas? Estas assunções são as de que os estados são os únicos atores importantes, a força militar é o instrumento principal e a segurança é o fim dominante. Invertendo isto, podemos postular um tipo de política mundial bastante diferente:

1) os estados não são os únicos atores importantes - os atores transnacionais a operarem através das fronteiras são igualmente intervenientes importantes;

2) a força não é o único instrumento significativo - a manipulação econômica e a utilização de instituições internacionais são os instrumentos mais importantes;

3) a segurança não é o fim dominante - o bem-estar é o objetivo dominante. (Nye Jr. 2002a, 233).

Joseph Nye Jr., no livro intitulado "O Paradoxo do Poder Americano", disserta sobre o poder econômico nas relações internacionais. No livro, Nye Jr. 


\section{Mauro Salvo}

define que Poder é a capacidade de obter os resultados desejados e, se necessário, mudar o comportamento dos outros para obtê-los. A capacidade de obter os resultados desejados freqüentemente vem associada à posse de certos recursos, por isso é comum simplificar a definição de poder como a posse de quantidades relativamente grandes de elementos tais como população, território, recursos naturais, vigor econômico, força militar e estabilidade política. (Nye Jr. 2002b, $30)$.

Tradicionalmente, o teste de uma grande potência costumava ser a força bélica. Hoje em dia, os fundamentos do poder têm se afastado da ênfase na força militar e na conquista. $O$ poder econômico tornou-se mais importante que no passado, tanto em virtude do aumento relativo do custo da força quanto porque os objetivos econômicos passaram a ganhar vulto nos valores das sociedades pós-industriais. (Nye Jr. 2002b, 35).

Tanto o poder militar como o econômico são exemplos do duro poder de comando que se pode empregar a fim de induzir os demais a mudarem de posição. $O$ poder bruto se apóia tanto em induções como em ameaças, mas existe um modo indireto de exercer o poder. Na política mundial, é possível que um país obtenha os resultados que quer porque os outros desejam acompanhálo, admirando os seus valores, imitando- lhe o exemplo, aspirando ao seu nível de prosperidade e liberdade. Neste sentido, é igualmente tão importante estabelecer a agenda na política mundial e atrair os outros, quanto forçá-los a mudar mediante a ameaça ou o uso das armas militares ou econômicas. A este aspecto do poder - levar os outros a querer o que você quer -, Nye Jr. dá o nome de "poder brando". Ele coopta as pessoas em vez de coagi-las. (Nye Jr. 2002b, $36)$.

$\mathrm{O}$ crescimento econômico provê não só a energia do poder bruto como também lustra o prestígio e a autoconfiança do país, contribuindo igualmente com o poder brando. (idem, 206). O crescimento econômico sustentado e não inflacionário gera os recursos que serão investidos em poder bruto, assim como um modelo econômico atraente, capaz de acrescer o nosso poder brando. A produtividade pode aumentar graças a novos investimentos em instrumentos ou a novas formas de organização. (Nye Jr. 2002b, 209).

As capacidades econômicas não podem ser separadas das outras capacidades dos estados. Os estados usam meios econômicos para fins militares e 
políticos; e meios militares e políticos para alcançar interesses econômicos. (Waltz 2002, 133-4). Na mesma linha de raciocínio, Brzezinski afirma que a habilidade econômica e sua tradução em inovação tecnológica podem ser também critérios chave na determinação do poder. (Brzezinski 1998, 46).

Kindleberger (1970, 55-56) apresentou alguns conceitos de poder econômico ressaltando que uma abordagem econômica para a política internacional deve considerar os aspectos econômicos do poder nacional. Em seguida alerta que o poder econômico pode existir nas relações internacionais sem ter sido desenhado como meio para controlar outras nações. Desta forma, é importante distinguir entre força econômica e poder econômico. A força econômica é um meio que pode ou não ser utilizado como poder para afetar outros países; enquanto poder econômico pode ser definido como sendo a força econômica utilizada para dominar ou controlar. A capacidade de afetar as decisões de outros seria chamada de influência e força seria o uso de meios físicos para afetar tais decisões. Kindleberger ainda apresenta seu conceito de domínio que seria a condição de o país A afetar as decisões de B (um ou vários países) sem que B possa afetar aquelas de $\mathrm{A}$.

Num mundo no qual a economia comanda e o uso do poder bruto é cada vez menos aceito, cresce o papel das instituições econômicas e da coerência de suas decisões. No caso do BACEN, os últimos anos confirmaram a importância de um modelo econômico eficaz. A persistência na busca pela estabilidade macroeconômica (iniciada com o advento do Plano Real - 1993) e a gestão da política econômica externa levou a economia brasileira a uma condição inédita. Nestes últimos quinze anos controlamos o processo inflacionário, acumulamos reservas internacionais, renegociamos a dívida externa, quitamos a parte da dívida com o FMI, reformamos o sistema financeiro nacional (PROER e PROES) e assim conquistamos a confiança do mercado financeiro internacional que aos poucos foi reconhecendo a solidez da economia brasileira e aumentando o ingresso de recursos no país.

Para o mercado internacional, o BACEN aumentou seu poder brando, pois tem provado sua capacidade de lidar com crises e manter-se no mesmo nível das autoridades monetárias das principais economias. Internamente, embora tenha melhorado sua imagem, ainda enfrenta resistências de alguns setores, principalmente por parte da indústria e pelo movimento sindical. 


\section{Mauro Salvo}

\section{Governança sem Governo e a Globalização}

Em dois séculos de globalização, as multinacionais, as nações, as sociedades e as regiões econômicas sofreram e continuarão sujeitas às mutações inerentes aos avanços tecnológicos das sociedades mais prósperas, mas certamente as prerrogativas do passado da teoria da dependência não servirão como método de análises, pois na globalização deste século haverá cada vez mais uma relação de interdependência entre países desenvolvidos e emergentes. (Lozardo 2007, 35).

Há novas dimensões na globalização, as quais estão causando transformações políticas e econômicas, principalmente entre as nações emergentes. Sem esse entendimento, torna-se difícil compreender o rumo das políticas comerciais, dos investimentos diretos internacionais, das referências do consumidor global, do papel das multinacionais, dos desafios dos empreendedores e dos governos de cada nação. Nesse sentido, as instituições internacionais do Ocidente, como a OMC, o Banco Mundial e o FMI, bem como as instituições regionais e os bancos centrais, estarão adotando políticas com o caráter da co-responsabilidade no tocante ao crescimento com maior abertura econômica, com a co-responsabiliade de cada governo no que diz respeito às políticas públicas, a transparências administrativas e das políticas de investimentos internacionais visando ao bem-estar de todos, à redução das discrepâncias e ao aumento de renda entre e intrapaíses. (Lozardo 2007, 35).

A globalização significa que existe um reconhecimento crescente de arenas cujos impactos são globais. É nessas arenas que é necessária uma ação coletiva global - e sistemas de governança global são essenciais. (Stiglitz 2002, $272)$.

Não existe um governo mundial, responsável pelos povos de todos os países e por supervisionar o processo de globalização. Em vez disso, temos um sistema que poderia ser chamado de governança global sem governo global, no qual algumas poucas instituições - o BM, o FMI, a OMC - e alguns participantes - os ministérios da fazenda (e bancos centrais) e do comércio, intimamente ligados a determinados interesses financeiros e comerciais dominam a cena. É o momento de mudar algumas das regras que governam a ordem econômica mundial, de dar menos ênfase a ideologias e de prestar mais atenção naquilo que realmente funciona, de pensar mais uma vez a respeito da 
maneira como as decisões são tomadas em nível internacional - e no interesse de quem. (Stiglitz 2002, 49).

O tema levantado por Stiglitz no parágrafo anterior introduz o problema da coordenação das ações globais, principalmente num ambiente de interdependência econômica. Tal problema ganhou importância na pauta dos assuntos internacionais quando as finanças internacionais tornaram o tema central das relações internacionais. Quando o assunto principal era a segurança nacional, o comportamento era mais previsível, pois tínhamos menos agentes (essencialmente Estados), menos variáveis e menor interdependência. Embora vivêssemos também numa sociedade anárquica, estava mais clara a condição de líder, seus aliados, as ameaças e havia uma melhor possibilidade de quantificar lucros e perdas decorrentes dos movimentos dos agentes. A coordenação do sistema internacional, mesmo não sendo formal, era tácita.

Continuamos numa sociedade anárquica, todavia sendo a economia o motor da política internacional, outros agentes não-estatais ganharam força (empresas, bancos, mercados emergentes, ONGs, organizações terroristas etc). Havendo mais agentes, há mais interesses em jogo, mais variáveis, aumenta a dificuldade de coordenação, pois o papel de liderança fica difuso, e diminui a previsibilidade. Os ganhos e perdas (pay-offs) das interações não são claros dificultando o estabelecimento da cooperação internacional.

Anteriormente, o jogo internacional podia ser comparado a um jogo de damas com um único tipo de peça (os Estados) fazendo somente um tipo de movimento (defender o interesse nacional). Atualmente o jogo mais apropriado para descrever as relações internacionais seria o xadrez com vários tipos de peças (agentes estatais e não estatais) fazendo movimentos diferentes (cada qual em defesa de seu interesse próprio).

Atualmente as bases para a cooperação financeira internacional são mais débeis que nos anos 70 e 80. Se nos preocupa a estabilidade do SFI, é importante que compreendamos quais são os pontos débeis de seus fundamentos e o porquê dos mesmos. O ritmo das inovações tecnológicas no mundo das finanças tem sido muito acelerado e a magnitude e relevância tem crescido ostensivamente no âmbito econômico; sem embargo, a capacidade política para ajustar-se a estas mudanças vem decrescendo. $O$ principal problema das finanças internacionais é que ela é dirigida por muitas mãos (governos, organizações internacionais e autoridades nacionais). (Strange 1999, 57). 


\section{Mauro Salvo}

Em todos estes temas o sistema político internacional, baseado no princípio obsoleto da soberania dos Estados territoriais, se encontra num estado de lamentável atraso com respeito a uma economia de mercado mundial, de grande poder, porém com pouco sentido da responsabilidade social e moral (Strange 1999, 57-8).

No livro "Globalização" George Soros pondera sobre as vantagens e desvantagens da globalização. Para Soros, os mercados financeiros internacionais construíram um campo de jogo desnivelado, que se tornou insustentável em sua atual forma (Soros 2003, 29).

Não existe equivalente internacional ao processo político que ocorre no âmbito dos diferentes Estados. Enquanto os mercados se tornaram globais, a política manteve-se firmemente arraigada na soberania do Estado. Ainda que anacrônico, o conceito de soberania continua sendo a base de sustentação das relações internacionais. É preciso aceitá-lo como ponto de partida para a criação da sociedade aberta (Soros 2003, 50, 186).

O que é então soberania? Dizer que um estado é soberano significa que ele decide por si mesmo como irá enfrentar os seus problemas internos e externos, incluindo se quer ou não procurar a assistência de outros e ao fazê-lo limitar a sua liberdade chegando a compromissos com eles. Os estados desenvolvem as suas próprias estratégias, cartografam os seus próprios caminhos, tomam as suas próprias decisões sobre como responder a qualquer necessidade que tenham ou quaisquer desejos que desenvolvam. Não é mais contraditório dizer que os estados soberanos são sempre constrangidos e, muitas vezes, muito constrangidos do que dizer que indivíduos livres, muitas vezes, tomam decisões sob a imensa pressão dos acontecimentos (Waltz 2002, 136).

\section{Reforma do Sistema Financeiro Internacional}

Nesta seção apenas consideraremos a reforma do sistema financeiro internacional, restringindo o que foi tratado na seção anterior ao que concerne às organizações como FMI e BM. No entanto não se deve esquecer que as relações econômicas e financeiras internacionais ocorrem dentro e fora destas instituições, com ou sem governança, com cooperação ou não. Dentro deste panorama tem o BACEN um importante papel. Nas palavras do geógrafo Milton Santos: "São o Banco Central e o Ministério da Fazenda, em combinação 
com as instituições financeiras internacionais, que orientam as grandes reformas ora em curso" (Santos 2001, 105).

José Antonio Ocampo no livro "La reforma del sistema financiero internacional: un debate en marcha" desenvolve seus argumentos sobre a reforma do sistema financeiro internacional. A controvérsia que surge em torno da discussão sobre a reforma do sistema financeiro internacional recai na possibilidade de contestar algumas das instituições financeiras nacionais em nível global, assim como aos efeitos do regulamento financeiro internacional sobre as políticas nacionais. Neste ponto que entra os bancos centrais nacionais e a medição de forças no sentido de se garantir maior espaço no cenário econômico mundial (Ocampo 1999, 31).

No que se refere à reforma do sistema financeiro internacional Ocampo ressalta que para ser relevante esta deve ser quatro pressupostos básicos. Em primeiro lugar, deve-se reconhecer que os problemas de informação que determinam a volatilidade financeira são de difícil solução, haja vista estarem associadas mais a volatilidade de opiniões e expectativas que a imperfeições dos fluxos de informação. Em segundo lugar, a reforma deve contar com o uso de medidas nacionais voltadas a reduzir a volatilidade para que não se corra o risco de adotar mecanismos que aprofundem os efeitos recessivos das crises financeiras. Em terceiro lugar, deve buscar a articulação, respeitando a soberania das políticas e instituições nacionais. Por último, deve-se ter presente que as distintas soluções não são neutras em termos dos equilíbrios nas relações econômicas internacionais, fato de especial importância para os países pequenos e em vias de desenvolvimento. (Ocampo 1999, 33-39).

Há quase consenso de que a freqüência cada vez maior das crises financeiras internacionais demonstra a existência de falhas nas instituições que regulam o mundo financeiro cada vez mais sofisticado, todavia instável. Em suma, tais instituições precisam estar mais adequadas à globalização financeira. (Ocampo 1999, 31).

Seria irreal defender grandes mudanças na atual estrutura do sistema financeiro internacional. $O$ poder relativo dos diferentes países talvez mude com o tempo, mas os EUA não abdicarão de sua posição, tampouco os demais países serão capazes de rebelar-se contra essa situação. Os países da periferia decerto sentem as dores infligidas pelo sistema, mas optar por sair talvez seja ainda mais doloroso. A atual arquitetura financeira sem dúvida é imperfeita e seu 


\section{Mauro Salvo}

aprimoramento beneficiaria todos os membros, inclusive os EUA. Deve-se promover maior equilíbrio entre prevenção de crises e intervenção nas crises e entre estímulos aos países que adotam políticas sadias e punição aos países que não fazem o dever de casa. (Soros 2003, 155-6).

Outro tema a tratar é como e por que o equilíbrio de poder entre a economia de mercado e a autoridade política conferida a estes Estados mudou tanto durante a segunda metade do século XX. Normalmente, esta mudança se definiu com o termo impreciso de globalização e constitui um tema de debate continuo, especialmente entre os especialistas em relações internacionais, comércio internacional e economia política internacional. Quais são as relações políticas chaves que podem afetar o sistema financeiro internacional, para melhor ou para pior? Foi alterado nos últimos tempos? (Strange 1999, 58).

Existem duas razões para regular o comportamento dos operadores e dos mercados financeiros internacionais: moderar e conter a cobiça e moderar e conter o medo. Ou os operadores têm cobiça e tomam riscos em demasia ou têm medo dos riscos tomados no passado. (Strange 1999, 163).

Há basicamente duas escolas de pensamento sobre o que se deve fazer para assegurar maior estabilidade e segurança no sistema financeiro internacional. Em linhas gerais a idéia predominante no BIS é que os banqueiros e outros atores financeiros são suficientemente racionais para moderar sua própria cobiça e dominar seus medos, de tal maneira que seja possível confiar em que utilizem a informação técnica e os métodos de avaliação de risco de que dispõem para se autocontrolar. A escola mais ligada ao pensamento predominante no FMI acredita na cooperação intergovernamental para reproduzir em nível internacional o tipo de mecanismos reguladores desenvolvidos nos Estados e até então utilizados por eles para disciplinar os sistemas bancário e financeiro. (Strange 1999, 163).

Uma vez que os reguladores nacionais têm sido vencidos pelas forças da inovação e da integração financeiras que espaçaram de seus controles, o centro de atenção se desloca para as possibilidades de estabelecer sistemas de controles negociados em nível internacional. Dentre outros problemas globais, a regulação financeira é um dos mais urgentes e por isso que instituições internacionais como o BIS e o FMI têm se ocupado do tema já há alguns anos. (Strange 1999, 183). 
Ethan Kapstein propõe que se poderia criar uma estrutura para governar as finanças internacionais de dois níveis combinando os sistemas reguladores nacionais num nível inferior com cooperação internacional num nível superior através do FMI e BIS. Strange mostra-se cética quanto à proposta de Kapstein, argumentando que a evidência é que os bancos se identificam com seus Estados quando necessitam apoio, porém evitam as autoridades reguladoras sempre que têm em vista algum benefício. No âmbito financeiro, a inovação, a liberalização e a feroz concorrência entre bancos e outras empresas privadas alteraram o delicado equilíbrio entre controles interestatais e nacionais. (Strange 1999, 203). No entanto, o posicionamento de Strange, antes de contrapor, parece reforçar a proposta de Kapstein, tendo em vista que se ambos se enfraqueceram resta pouca alternativa à cooperação entre os dois níveis.

Strange sintetiza suas idéias em cinco conclusões sobre a volatilidade financeira global. Para o fim deste trabalho citamos apenas duas. A primeira é que todas as atividades da economia real seguem o humor dos mercados financeiros. A segunda é que os governos têm menos controle sobre suas economias e sociedades do que tinham há 10, 20 ou 30 anos. (Strange 1999, 2078).

\section{Jogos em Dois Níveis: arena interna versus arena externa}

Toda teoria das Relações Internacionais carece de uma definição do nível de análise (Estados ou regiões ou o próprio sistema internacional), juntamente com a definição ontológica da teoria (o que é a estrutura das relações internacionais?). A primeira questão refere-se a quem são os agentes das relações internacionais e, a segunda, à estrutura das relações internacionais. Após a definição de quem e o quê, deve-se definir qual a relação entre agente e estrutura.

As políticas internas e externas se tornaram inextricavelmente ligadas por um fio tênue. As interações dos grupos políticos internos podem revelar-se úteis dentro do exercício da diplomacia. Os governos aproveitam destas interações para fixar limites de concessões que podem fazer sob pena de sofrer rejeição popular. As interações internas se tornam instrumentos de política 


\section{Mauro Salvo}

exterior que os negociadores utilizam para marcar suas posições. De maneira paralela, as negociações internacionais constituem alavancas de política interna. Elas servem para justificar reformas impopulares. (Landau 1996, 169-170).

Cada Estado chega a políticas e decide sobre ações de acordo com os seus próprios processos internos, mas as suas decisões são moldadas pela presença de outros estados assim como pelas interações com eles. (Waltz 2002, 95).

Os Estados, ou aqueles que atuam por eles, tentam, de formas mais ou menos sensatas, usar os meios disponíveis de modo a alcançar os fins em vista. Waltz reconhece que a teoria de política internacional deve ser complementada por teoria de política doméstica. A configuração política interna oferece o filtro para a compreensão dos condicionantes estruturais e para a decisão da ação internacional. (Waltz 2002, 164).

Robert Putnam (1988) destaca que muitas vezes as decisões de políticas domésticas estão entrelaçadas às negociações internacionais. Putnam ainda ressalta que as políticas de muitas negociações internacionais podem ser concebidas como um jogo de dois níveis. No nível doméstico, grupos perseguem seus interesses pressionando o governo a adotar políticas favoráveis e políticos buscam poder construindo coalizões entre esses grupos. No nível internacional, governos nacionais buscam maximizar suas próprias habilidades para satisfazer as pressões domésticas enquanto minimizam as conseqüências dos desenvolvimentos externos. Nenhum dos dois jogos pode ser ignorado pelo tomador de decisões central, assim como seus países permanecem interdependentes, mesmo que soberanos.

Putnam descreveu os dirigentes políticos como situados entre duas mesas: 1) a da negociação internacional, tanto em situações de crise como fora delas; 2) a das pressões das forças políticas internas.

$\mathrm{O}$ trajeto diplomático a percorrer tem de ser adaptado àquilo que os demais Estados acharão aceitável, mas também àquilo que os diversos constituintes domésticos podem ser persuadidos a aceitar.

Stiglitz faz defesa da cooperação internacional e do multilateralismo afirmando que, em nível internacional, a teoria identifica por que governos individuais talvez deixem de servir ao bem-estar econômico global, e de que maneira a ação coletiva global - uma ação conjunta de vários governos 
trabalhando unidos, geralmente por meio de instituições internacionais melhoraria a situação. (Stiglitz 2002, 243).

Dougherty e Pflatzgraff (2003) relatam que muitos autores apresentam elementos comuns no que toca aos quadros mentais que utilizam para analisar os sistemas internacionais. Em primeiro lugar, a maioria deles demonstra interesse nos fatores que contribuem para a estabilidade ou instabilidade do sistema internacional. Em segundo lugar, existe uma preocupação comum com os mecanismos adaptativos que permitem ao sistema permanecer em equilíbrio e estabilidade. Em terceiro lugar, existe um interesse comum na avaliação do impacto sobre o sistema relativo à presença de unidades com diferentes capacidades de mobilizar recursos e de utilizar tecnologia avançada. Em quarto lugar, existem muitos autores que concordam acerca do fato de que as forças que se movem dentro das unidades políticas nacionais exercem uma grande influência no sistema internacional. Em quinto lugar, estes autores mostram-se interessados, até como parte do seu interesse pela natureza do equilíbrio, com a capacidade do sistema internacional de conter e tratar de forma eficaz os distúrbios que se desenvolvem no seu interior. Isto conduz a um interesse partilhado pelo papel dos atores nacionais e supranacionais enquanto reguladores, num sistema internacional caracterizado pela mudança dinâmica. (Dougherty e Pfaltzgraff Jr. 2003, 154).

O dilema de tomar decisões em duas arenas - interna e externa - é enfrentado pelo BACEN quando este regulamenta e fiscaliza o sistema bancário e creditício, quando negocia a dívida externa, quando administra as reservas internacionais, quando regulamenta e fiscaliza o mercado de câmbio, quando estabelece a taxa de juros básica da economia brasileira. Em todas essas decisões pesam a estrutura do sistema financeiro internacional e as demandas da sociedade brasileira.

\section{Reformas Institucionais Domésticas}

Um debate pertinente, que pode ser analisado pela ótica dos dois níveis, refere-se ao formato das instituições domésticas. Um país que opte pelo não isolacionismo deve desenvolver instituições condizentes não só com o meio e os fins desejados para seu próprio país, mas também estar em consonância com aquilo que se espera obter nas relações com o resto do mundo. Em outras 


\section{Mauro Salvo}

palavras, não se pode esperar obter vantagens das relações internacionais se suas instituições domésticas não estiverem preparadas para tanto.

As nações em desenvolvimento devem elas mesmas assumir responsabilidade por seu próprio bem- estar. Podem gerir seus orçamentos para que vivam dentro de suas possibilidades, por mais parcas que possam ser, e eliminar as barreiras protecionistas que embora possam gerar grandes lucros para alguns poucos, forçam consumidores a pagar preços mais altos. Podem implementar regulamentação rigorosa tanto para se protegerem de especuladores de fora quanto de mau comportamento corporativo interno. Mais importante: os países em desenvolvimento precisam de governos eficazes, com judiciários fortes e independentes, responsabilização democrática, abertura e transparência, bem como o fim da corrupção que vem sufocando a eficácia do setor público e o crescimento do setor privado. (Stiglitz 2002, 302).

Exatamente quais instituições hão de entrar no pacote da "boa governança" é coisa que varia de uma recomendação para outra, mesmo porque ainda não se conseguiu entender a relação entre determinadas instituições e o desenvolvimento econômico. Em todo caso, esse pacote de "instituições boas" geralmente inclui a democracia, uma burocracia e um Judiciário limpos e eficientes; a forte proteção ao direito de propriedade (privada), inclusive de propriedade intelectual; boas instituições de governança empresarial, sobre tudo as exigências de divulgação de informação e a Lei de Falência; e instituições financeiras bem desenvolvidas. (Chang 2003, 124).

Nem toda sociedade compartilha do entendimento de que a inserção em um mundo economicamente globalizado, integrado e interconectado, é o melhor caminho para acelerar o progresso material da nação. Essa inserção, particularmente para os países emergentes, requer, antes da fase de inserção na economia global, a feitura de reformas macro e microeconômicas que promulgam mudanças nas tradições de poder político- econômico de grupos de interesses. (Lozardo 2007, 42).

Por vezes, o desenvolvimento institucional foi adiado em virtude da interdependência de certas instituições, de modo que foi necessário que as instituições relacionadas se desenvolvessem simultaneamente. (Chang 2003, $200)$. 
De certo modo ocorre atualmente no Brasil aquilo que Chang prevê. Talvez seja por isso que no caso do BACEN haja tantas críticas, pois este optou por preparar-se e integrar-se às relações econômicas internacionais. Pode-se discutir com qual representatividade foi tomada tal decisão, todavia fato é que o BACEN tem adotado políticas mais afeitas a estrutura vigente nas finanças internacionais.

\section{Por que o BACEN se tornou um ator importante nas relações internacionais}

O cenário internacional das últimas cinco décadas tanto resultou como foi resultado da solução de diversos conflitos em favor de uma maior institucionalização. Em linhas gerais, conflitos como democracia ou grupos de poder, transparência ou discurso falacioso, solução técnica ou política, estado ou governo, instituições ou conchavo, estabilidade ou crescimento foram sendo decididos em favor dos primeiros. Desta forma, as instituições que priorizaram ou passaram a priorizar, com o passar do tempo, as soluções técnicas, transparentes e democráticas ganharam evidência. Foi o caso do BACEN.

Desde que foi criado em 1964, as atividades do BACEN estiveram estreitamente ligadas à política exterior brasileira e em decorrência às relações internacionais. Sinteticamente podemos associar a própria criação do BACEN à decisão política de desenvolver a economia brasileira e à necessidade de romper com a relação centro-periferia da política internacional da época.

$\mathrm{Na}$ área econômica, o início dos anos 1960 foi marcado por uma queda dos investimentos e da taxa de crescimento da renda brasileira. Era praticamente consenso na época a necessidade de reformas institucionais que formassem um quadro favorável à retomada dos investimentos. Foi então lançado o PAEG (Plano de Ação Econômica do Governo) cujas principais reformas foram a tributária, a monetária e financeira e a do setor externo.

Dentre as várias medidas adotadas pelo PAEG destaca-se para o objetivo deste trabalho a reforma do setor externo que tinha por finalidade estimular o desenvolvimento econômico, evitando pressões sobre o Balanço de Pagamentos por meio da melhora do comércio externo e da atração de capital estrangeiro. No tocante ao comércio exterior, adotou-se uma série de incentivos fiscais para a exportação e o sistema de minidesvalorizações cambiais para manter competitividade externa. Quanto à atração de capital estrangeiro, buscou uma reaproximação com a política externa norte-americana, a chamada 


\section{Mauro Salvo}

Aliança para o Progresso². Em seguida, efetuou-se a renegociação da dívida externa e firmou-se um Acordo de Garantias (1965) para o capital estrangeiro. As ligações com o sistema financeiro internacional foram feitas através de dois mecanismos, ambos ficaram a cargo do BACEN: a Lei $\mathbf{n}^{\circ} 4.131$, que dava acesso direto das empresas ao sistema financeiro internacional, e a Resolução $\mathbf{n}^{\circ} 63$, que possibilitava a captação de recursos externos pelos bancos comerciais e de investimento para repasse interno. Esta última significava a colagem do sistema financeiro nacional ao internacional e o início do processo de internacionalização financeira no Brasil. (Gremaud 1999, 250-1).

Durante o governo Costa e Silva (1967-69), a Chancelaria tornava público que a finalidade era colocar a ação diplomática a serviço do desenvolvimento mediante o máximo aproveitamento das oportunidades. $\mathrm{O}$ setor externo torna-se estratégico em termos de comércio, capital e tecnologias, mas não se deveria alimentar ilusões. A ordem internacional do pós-guerra corresponde a um mecanismo de entorpecimento dos esforços de desenvolvimento das nações menos desenvolvidas e a distensão indica a distribuição do poder em esferas de influência sob domínio das duas superpotências. (Cervo 1994, 44).

$O$ congelamento do poder mundial, que perpetua os mecanismos das relações internacionais, era visto como o elemento mais adverso aos interesses do Brasil, porque obstruía a abertura do sistema, impedindo a penetração e a construção de um espaço brasileiro. A nação emergente fazia o papel do intruso indesejado. $\mathrm{O}$ Brasil requisitava maior parcela de poder para usá-lo em favor de seu desenvolvimento. (Cervo 1994, 44-5).

Soberania e desenvolvimento foram proclamados como a essência da orientação diplomática. Ao captar a conjuntura mundial, constatava o ministro das Relações Exteriores o deslocamento da zona de tensão do centro para a periferia, o equilíbrio nuclear e o decorrente afastamento do risco de guerra mundial. No econômico, observava a oposição entre o Norte desenvolvido e o

${ }^{2}$ A Aliança para o Progresso foi o principal programa de política externa dos Estados Unidos no início da década de 1960. Ela representou o enfrentamento do 'perigo' comunista que teria se instalado na América Latina com a Revolução Cubana em 1959. Dada sua importância geopolítica, o Brasil foi o país latinoamericano prioritário para a ação do programa. 
Sul subdesenvolvido, numa bissegmentação cujo processo foi concomitante à dissolução do universo bipolar do pós-guerra. $\mathrm{O}$ interesse material e o bem-estar das populações dos respectivos Estados eram os critérios prevalecentes na política mundial. A consciência dessa realidade levava a não aceitação de alinhamentos incondicionais ou oposições sistemáticas. (Bueno 1994, 92).

Na década de 1970 quando a política econômica foi baseada na idéia do "exportar é o que importa" a política cambial passa a ser de vital importância e por tratar-se de atribuição do BACEN cresce a importância deste órgão. A década também foi marcada pelo "milagre" econômico brasileiro seguido do primeiro choque do petróleo, aumento da dívida externa, segundo choque do petróleo e conseqüente cenário externo desfavorável.

A década de 1980 foi marcada pela crise da dívida externa com reflexos tão negativos para a economia brasileira que ficou conhecida como "a década perdida". Destaca-se um dado básico que caracteriza o final do período militar: a condição de grande devedor assumida pelo País. Em razão do protecionismo dos países industrializados, dos problemas decorrentes da queda nos preços dos produtos de base nos anos anteriores e, principalmente, do aumento das taxas de juros, cresceu de maneira assustadora a dívida externa do Terceiro Mundo em geral e a do Brasil em particular, que promovera seu desenvolvimento na década anterior à base de maciço aporte de capitais externos. Na década de 1970, o conjunto da economia brasileira passou a depender, como até então não se observara, do seu setor externo. O afluxo de capitais (na forma de empréstimos de bancos particulares, bancos nacionais e instituições financeiras internacionais e de investimentos privados diretos) e o volume das exportações e das importações contribuíram para elevar o PNB do Brasil à oitava posição no Ocidente, mas provocaram, juntamente com a crise do petróleo, a acumulação de enorme dívida externa. $O$ último governo militar descartou o recurso à moratória e encaminhou o assunto pelas vias e modos tradicionais e em separado dos demais credores. Embora advogasse pela via diplomática multilateral a necessidade de uma decisão política nas negociações, a política do País neste aspecto foi transferida para os ministérios do Planejamento e da Fazenda. (Bueno 1994, 94).

Nos anos 80 houve vários episódios que exigiram a ação do BACEN na arena internacional. A crise da dívida externa e o início do processo de sua renegociação, o recrudescimento da inflação e a implantação de vários planos de 


\section{Mauro Salvo}

estabilização, o início da globalização e o Acordo de Basiléia I. Os bancos centrais que aderiram ao acordo comprometeram-se a adotar as práticas de regulamentação financeira aceitas internacionalmente como as melhores. Embora não haja nenhum poder para forçar os países a aderirem ao acordo, ou mesmo a efetivamente praticarem os princípios previstos, a assinatura deste e sua implementação de fato confere ao sistema financeiro local um selo de garantia tácito que ajuda a receber recursos externos.

Na década de 1990, o processo de globalização se acentua com o fim da Guerra Fria, acordo sobre dívida externa, arrefecimento do processo inflacionário e o Acordo de Basiléia II. Na década de 2000, temos a adoção de sistema de metas de inflação, combate à lavagem de dinheiro e a discussão sobre adotar ou não controles de capitais. Como se pode observar o BACEN esteve atuante nos temas econômicos de maior relevância tanto interna como externamente (se é que é possível separá-los desta forma).

A tabela abaixo apresenta a evolução de alguns fluxos que mostram a crescente internacionalização da economia brasileira e, por conseguinte, do Banco Central do Brasil. Estes números em algumas ocasiões foram impactados pela ação do BACEN e em outras exigiu sua reação como órgão regulador.

Tabela 1: Evolução de alguns fluxos nas últimas décadas

\begin{tabular}{|l|c|l|l|l|}
\hline Descrição dos fluxos & \multicolumn{1}{|c|}{$\mathbf{1 9 8 0}$} & \multicolumn{1}{|c|}{$\mathbf{1}$} & \multicolumn{1}{c|}{$\mathbf{2 0 1 0}$} \\
\hline Exportação de bens & $20.132,40$ & $31.413,76$ & $55.085,59$ & $201.915,29$ \\
\hline Importação de bens & $22.955,17$ & $20.661,36$ & $55.783,34$ & $181.768,43$ \\
\hline Fluxo de comércio & $43.087,57$ & $52.075,12$ & $110.868,94$ & $383.683,71$ \\
\hline Investimento brasileiro direto & 366,50 & 624,60 & $2.281,59$ & $11.587,57$ \\
\hline Investimento estrangeiro direto & $1.910,20$ & 988,80 & $32.779,24$ & $48.506,49$ \\
\hline Investimento brasileiro em carteira & ---------- & 106,60 & $1.695,72$ & $4.783,92$ \\
\hline Investimento estrangeiro em carteira & 350,80 & 578,87 & $8.650,78$ & $67.794,86$ \\
\hline Reservas internacionais (estoque) & $6.913,00$ & $9.973,00$ & $33.011,00$ & $288.575,00$ \\
\hline Empréstimos e financiamentos - Ingresso & $12.049,00$ & $2.797,20$ & $15.925,96$ & $34.556,11$ \\
\hline
\end{tabular}

Fonte: Banco Central do Brasil

Em todos os dados apresentados na tabela acima se pode notar um exponencial crescimento a partir da década de 90. Pode-se inferir que tal 
comportamento seja resultado da inserção da economia brasileira num ambiente mais internacional através de mudanças institucionais.

\section{Considerações Finais}

Considerando-se os estados nacionais como os principais agentes das relações internacionais, mesmo reconhecendo-se não serem mais os únicos e exclusivos, e sendo o BACEN parte do Estado, não há como negar sua influência na política externa brasileira.

Além disso, o BACEN age no campo externo representando o país como um todo dentro dos organismos internacionais, perante empresas estrangeiras, tanto financeiras como não-financeiras, e como consultor do Ministério das Relações Exteriores com voz e influência nas decisões do Estado brasileiro.

Portanto, difícil refutar a hipótese de que o BACEN seja um ator das relações internacionais do Brasil. Da mesma forma que é difícil, quiçá impossível, citar outra instituição mais inserida na problemática externa do país. Além disso, não há instituição estatal atuante no cenário internacional que esteja desconectada da realidade de seu Estado de origem, portanto estas sempre atuarão tanto no nível interno quanto no externo. Pode haver instituições meramente domésticas, mas é difícil imaginar uma instituição exclusivamente internacional. 


\section{Mauro Salvo}

\section{REFERÊNCIAS}

Bueno, C. 1994. “A Política Multilateral Brasileira”. In O Desafio Internacional, editado por Amado Luiz Cervo. Brasília: Editora UnB.

Brzezinski, Z. 1998. El Gran Tablero Mundial: la supremacía estadounidense y sus imperatives geoestratégicos. Barcelona: Ediciones Paidós Ibérica.

Cervo, A. 1994. "Relações Internacionais do Brasil". In O Desafio Internacional, editado por Amado Luiz Cervo. Brasília: Editora UnB.

Chang, H. 2003. Chutando a Escada: a estratégia de desenvolvimento em perspectiva histórica. São Paulo: Editora Unesp.

Dougherty, J. E.; and R. L. Pfaltzgraff Jr. 2003. Relações Internacionais: as teorias em Confronto. Lisboa: Gradiva.

Gremaud, A. et al. 1999. Economia Brasileira Contemporânea. São Paulo: Editora Atlas.

Griffiths, M. 2004. 50 Grandes Estrategistas das Relações Internacionais. São Paulo: Contexto.

Keohane, R. O.; and J. Nye Jr. 1993. "Power and Interdependence". Survival 15(4): 158-165.

Kindleberger, C. 1970. Power and Money: the economics of international politics and the politics of international economics. Nova Iorque: Basic Books.

Landau, A. 1996. Conflits et Cooperation dans les Relations Economiques Internationales. Paris: Bruylant.

Lozardo, E. 2007. Globalização: a certeza imprevisível das nações. São Paulo: Editora do Autor.

Nye Jr., J. S. 2002. O Paradoxo do Poder Americano. São Paulo: Editora Unesp. . 2002. Comprender os Conflitos Internacionais: uma introdução à teoria e à História. Lisboa: Gradiva..

Ocampo, J. A. 1999. La reforma del sistema financiero internacional: un debate en marcha. Santiago: CEPAL.

Putnam, R. D. 1998. "Diplomacy and domestic politics; the logic of twolevel games". International Organization 42.

Santos, M. 2001. Por Uma Outra Globalização. São Paulo: Record.

Sarfati, G. 2005. Teoria das Relações Internacionais. São Paulo: Editora Saraiva.

Soros, G. 2003 Globalização. Rio de Janeiro: Editora Campus. 
Strange, S. 1988. States and Markets: an introduction to international political economy. Londres: Pinter.

. 1996. The Retreat of the State: the diffusion of power in the world economy. Cambridge: Cambridge University Press. . 1999. Dinero Loco. Buenos Aires: Ediciones Paidós.

Waltz, K. 2002. Teoria das Relações Internacionais. Lisboa: Gradiva. 


\section{Mauro Salvo}

\section{RESUMO}

O artigo tem como objetivo caracterizar o Banco Central do Brasil como um agente das Relações Internacionais e que suas ações tanto internas quanto externas têm alguma conotação política dada a impossibilidade de separar o econômico do político. Pretende-se demonstrar que a democratização, a globalização e a conscientização sobre a necessidade de aumentar a transparência nas relações financeiras, econômicas e políticas e o crescimento da cooperação internacional fortaleceram tanto as instituições internacionais como as domésticas ou aumentaram a necessidade de que os países que desejam inserir-se globalmente desenvolvam instituições fortes, entre elas, seus respectivos bancos centrais.

\section{PALAVRAS-CHAVE}

Banco Central; Poder Econômico; Relações Internacionais

Recebido em18 de julho de 2013. Aprovado em 25 de julho de 2013. 